NASA/TM-2005-213660

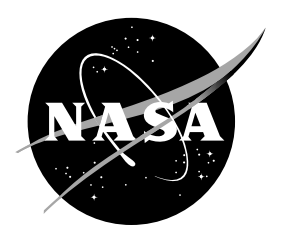

\title{
Performance Cycle Analysis of a Two-Spool, Separate-Exhaust Turbofan With Interstage Turbine Burner
}

K.H. Liew, E. Urip, and S.L. Yang

Michigan Technological University, Houghton, Michigan

J.D. Mattingly

Mattingly Consulting, Bothell, Washington

C.J. Marek

Glenn Research Center, Cleveland, Ohio 
Since its founding, NASA has been dedicated to the advancement of aeronautics and space science. The NASA Scientific and Technical Information (STI) Program Office plays a key part in helping NASA maintain this important role.

The NASA STI Program Office is operated by Langley Research Center, the Lead Center for NASA's scientific and technical information. The NASA STI Program Office provides access to the NASA STI Database, the largest collection of aeronautical and space science STI in the world. The Program Office is also NASA's institutional mechanism for disseminating the results of its research and development activities. These results are published by NASA in the NASA STI Report Series, which includes the following report types:

- $\quad$ TECHNICAL PUBLICATION. Reports of completed research or a major significant phase of research that present the results of NASA programs and include extensive data or theoretical analysis. Includes compilations of significant scientific and technical data and information deemed to be of continuing reference value. NASA's counterpart of peerreviewed formal professional papers but has less stringent limitations on manuscript length and extent of graphic presentations.

- TECHNICAL MEMORANDUM. Scientific and technical findings that are preliminary or of specialized interest, e.g., quick release reports, working papers, and bibliographies that contain minimal annotation. Does not contain extensive analysis.

- CONTRACTOR REPORT. Scientific and technical findings by NASA-sponsored contractors and grantees.
- CONFERENCE PUBLICATION. Collected papers from scientific and technical conferences, symposia, seminars, or other meetings sponsored or cosponsored by NASA.

- SPECIAL PUBLICATION. Scientific, technical, or historical information from NASA programs, projects, and missions, often concerned with subjects having substantial public interest.

- TECHNICAL TRANSLATION. Englishlanguage translations of foreign scientific and technical material pertinent to NASA's mission.

Specialized services that complement the STI Program Office's diverse offerings include creating custom thesauri, building customized databases, organizing and publishing research results ... even providing videos.

For more information about the NASA STI Program Office, see the following:

- Access the NASA STI Program Home Page at http://www.sti.nasa.gov

- E-mail your question via the Internet to help@sti.nasa.gov

- Fax your question to the NASA Access Help Desk at 301-621-0134

- Telephone the NASA Access Help Desk at 301-621-0390

- Write to:

NASA Access Help Desk

NASA Center for AeroSpace Information 7121 Standard Drive

Hanover, MD 21076 
NASA/TM-2005-213660

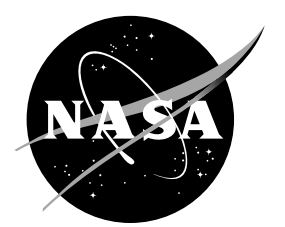

\section{Performance Cycle Analysis of a Two-Spool, Separate-Exhaust Turbofan With Interstage Turbine Burner}

K.H. Liew, E. Urip, and S.L. Yang

Michigan Technological University, Houghton, Michigan

J.D. Mattingly

Mattingly Consulting, Bothell, Washington

C.J. Marek

Glenn Research Center, Cleveland, Ohio

National Aeronautics and

Space Administration

Glenn Research Center 


\section{Acknowledgments}

The authors would like to thank NASA Glenn Research Center for its financial support.

This work was sponsored by the Low Emissions Alternative

Power Project of the Vehicle Systems Program at the NASA Glenn Research Center.

Available from

NASA Center for Aerospace Information 7121 Standard Drive

Hanover, MD 21076
National Technical Information Service 5285 Port Royal Road Springfield, VA 22100

Available electronically at http:/ /gltrs.grc.nasa.gov 


\title{
Performance Cycle Analysis of A Two-spool, Separate-exhaust Turbofan With Interstage Turbine Burner
}

\author{
K.H. Liew, E. Urip, and S.L. Yang \\ Michigan Technological University \\ Houghton, Michigan 49931-1200 \\ J.D. Mattingly \\ Mattingly Consulting \\ Bothell, Washington 98011 \\ C.J. Marek \\ National Aeronautics and Space Administration \\ Glenn Research Center \\ Cleveland, Ohio 44135
}

This paper presents the performance cycle analysis of a dual-spool, separate-exhaust turbofan engine, with an Interstage Turbine Burner serving as a secondary combustor. The $I T B$, which is located at the transition duct between the high- and the low-pressure turbines, is a relatively new concept for increasing specific thrust and lowering pollutant emissions in modern jet engine propulsion. A detailed performance analysis of this engine has been conducted for steady-state engine performance prediction. A code is written and is capable of predicting engine performances (i.e. thrust and thrust specific fuel consumption) at varying flight conditions and throttle settings. Two design-point engines were studied to reveal trends in performance at both full and partial throttle operations. A mission analysis is also presented to assure the advantage of saving fuel by adding ITB.

\section{Nomenclature}

$\begin{array}{ll}A & =\text { cross-sectional area } \\ a & =\text { sound speed } \\ F & =\text { uninstalled thrust } \\ f & =\text { fuel/air ratio, or function }\end{array}$ 


$$
\begin{array}{ll}
g_{c} & =\text { Newton's constant } \\
h_{P R} & =\text { low heating value of fuel } \\
M & =\text { Mach number } \\
\dot{m} & =\text { mass flow rate } \\
P & =\text { static pressure } \\
P_{t} & =\text { total pressure } \\
R & =\text { universal gas constant } \\
S & =\text { uninstalled thrust specific fuel consumption } \\
T_{t} & =\text { total temperature } \\
V & =\text { absolute velocity }
\end{array}
$$

$\underline{\text { Greek symbols }}$

$$
\begin{array}{ll}
\alpha & =\text { bypass ratio } \\
\gamma & =\text { specific heat ratio, } c_{p} / c_{v} \\
\eta & =\text { efficiency } \\
\pi & =\text { total pressure ratio } \\
\pi_{r} & =\text { ratio between total pressure and static pressure due to the ram effect, } P_{t} / P_{0} \\
\tau & =\text { total temperature ratio } \\
\tau_{r} & =\text { ratio of total temperature and static temperature due to the ram effect, } T_{t} / T_{0} \\
\tau_{\lambda} & =\text { ratio of burner exit total enthalpy to enthalpy at ambient condition }
\end{array}
$$

\section{$\underline{\text { Subscripts }}$}

$$
\begin{array}{ll}
b & =\text { main burner } \\
c & =\text { engine core, compressor, or properties at upstream of main burner } \\
c H & =\text { high pressure compressor } \\
c L & =\text { low pressure compressor } \\
d & =\text { diffuser } \\
f & =\text { fan } \\
i t b & =\text { ITB, or properties at downstream of ITB } \\
m & =\text { mechanical or constant value }
\end{array}
$$




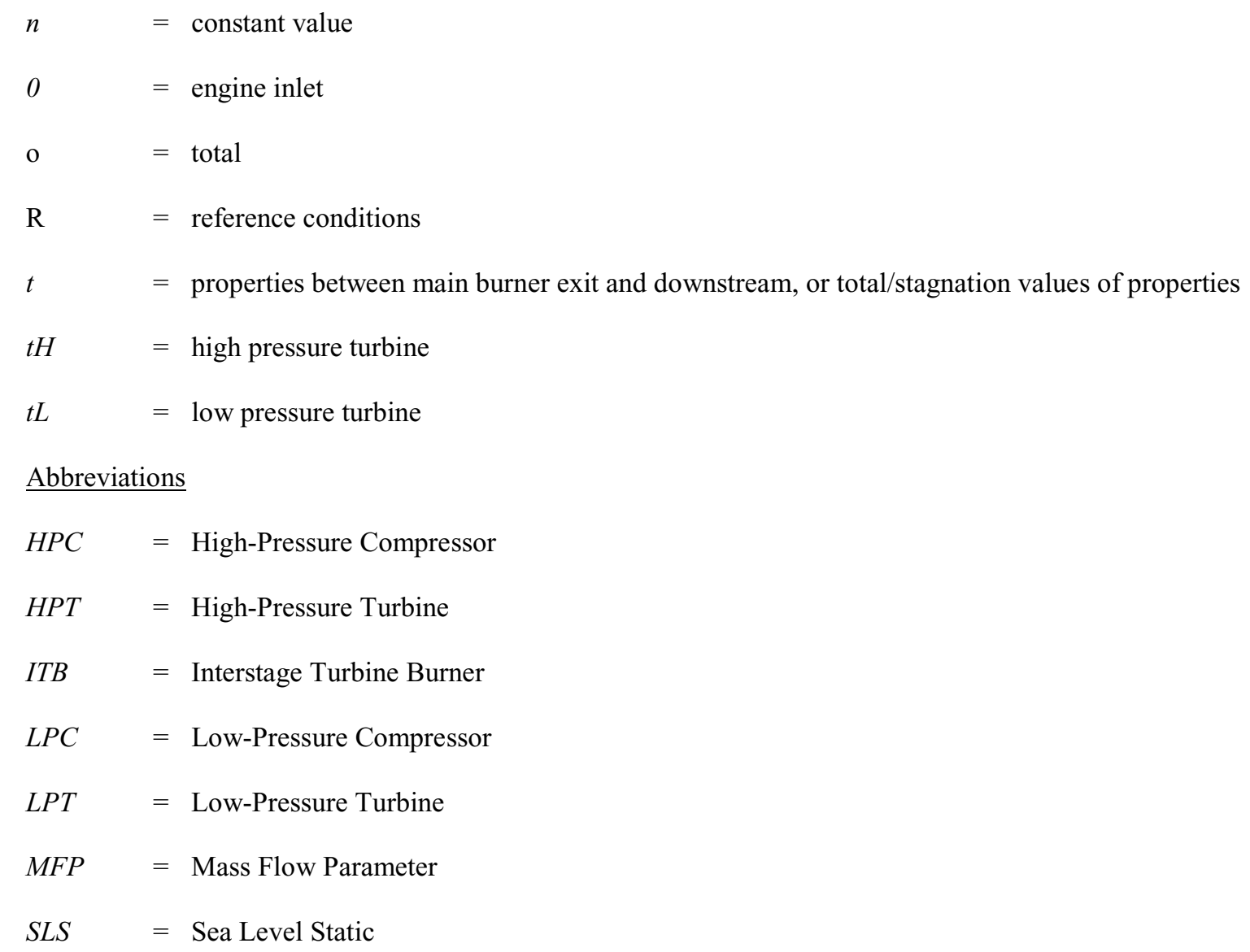

\section{Introduction}

Turbofan engine, a modern variation of the basic gas turbine engine, has gained popularity in most new jet-powered aircrafts, including military and civilian types. Basically, it is a turbojet engine with an addition of a fan. The fan causes more air to bypass the engine core and exit at higher speeds, resulting in greater thrust, lower specific fuel consumption and reduced noise level. Usually, the fan and low-pressure compressor $(L P C)$ are connected on the same shaft to a low-pressure turbine (LPT). This type of arrangement is called a two-spool engine.

Interstage Turbine Burner (ITB) is relatively a new concept in modern jet engine propulsion. Most commercial turbofan engines have a transition duct between the high-pressure turbine $(H P T)$ and the $L P T$. The ITB considered in this study is the placement of flame-holders inside the transition duct. ITB is also known as a reheat cycle $^{1}$, where the expanded gas from each 
expansion process in a turbine is reheated before the next expansion process, as shown in Fig. 1. In $I T B$, fuel is burnt at a higher pressure than a conventional afterburner, leading to a better thermal efficiency. The major advantages associated with the use of ITB are an increase in thrust and potential reduction in $\mathrm{NO}_{\mathrm{x}}$ emission ${ }^{2}$. Recent studies on the turbine burners can be found in the literature, see for example, Liew et $\mathrm{al}^{2}$, Sirignano and $\mathrm{Liu}^{3,4}$, and Vogeler ${ }^{5}$, However, these studies are limited to parametric cycle analysis only, which is also known as on-design analysis.

The work presented here is a systematic performance cycle analysis of a dual-spool, separateexhaust turbofan engine with an ITB. Performance cycle analysis is also known as off-design analysis. It is an extension work for the previous study ${ }^{2}$, i.e. on-design cycle analysis, in which we showed how the performance of a family of engines was determined by design choices, design limitations, or environmental conditions ${ }^{6}$.

In general, off-design analysis differs significantly from on-design analysis. In on-design analysis, the primary purpose is to examine the variations of specific engine performance at a flight condition with changes in design parameters, including design variables for engine components. Then, it is possible to narrow down the desirable range for each design parameter. Once the design choice is made, it gives a so-called reference-point (or design-point) engine for a particular application. Off-design analysis is then performed to estimate how this specific reference-point engine will behave at conditions other than those for which it was designed. Furthermore, the performance of several design-point engines can be compared to find the most promising engine that has the best balanced performance over the entire flight envelope.

\section{Approach}

The station numbering for the turbofan cycle analysis with ITB is in accordance with APR $755 \mathrm{~A}^{7}$ and is given in Fig. 2. The ITB (the transition duct) is located between station 4.4 and 4.5. 
The resulting analysis gives a system of eighteen nonlinear algebraic equations and equations for $A_{4.5}$ and $A_{8}$ that are solved for the dependent variables. Table 1 gives the variables and constants in this analysis. As will be shown, specific values of the independent variables $m$ and $n$ are desirable. Thus the number of independent variables is reduced to 5 and the number of dependent variables increased to 20 .

\section{Off-design Cycle Analysis}

The following assumptions are employed:

1) The working fluid is air and products of combustion which behaves as perfect gases.

2) All component efficiencies are constant;

3) The area at each engine station is constant, except the areas at station 4.5 and 8 ;

4) The flow is choked at the $H P T$ entrance nozzles (station 4), at LPT entrance nozzles (station 4.5), and at the throat of the exhaust nozzles (station 8 and 18).

5) At this preliminary design phase, turbine cooling is not included.

An off-design cycle analysis is used to calculate the uninstalled engine performance. The methodology is similar to those described in Mattingly ${ }^{8,9}$. Two important concepts are mentioned here to help explain the analytical method.

The first is called referencing, in which the conservation of mass, momentum, and energy are applied to the one-dimensional flow of a perfect gas at an engine steady-state operating point. This leads to a relationship between the total temperatures $(\tau)$ and pressure ratios $(\pi)$ at a steady-state operating point, which can be written as $f(\tau, \pi)$ equal to a constant. The referencepoint values (subscript ' $R$ ') from the on-design analysis can be utilized to give value to the constant and allow one to calculate the off-design parameters, as described below:

$$
f(\tau, \pi)=f\left(\tau_{R}, \pi_{R}\right)
$$


The second concept is the mass flow parameter $(M F P)$, where the one-dimensional mass flow property per unit area can be written in the following functional form:

$$
M F P=\frac{\dot{m} \sqrt{T_{t}}}{P_{t} A}=M \sqrt{\frac{\gamma g_{c}}{R}}\left(1+\frac{\gamma-1}{2} M^{2}\right)^{\frac{\gamma+1}{2(1-\gamma)}}
$$

This relation is useful in calculating flow areas, or in finding any single flow quantity, provided the other four quantities are known at that station.

\section{Component Modeling}

In off-design analysis, there are two classes of predicting individual component performance. First, actual component characteristics can be obtained from component hardware performance data, which give a better estimate. However, in the absence of actual component hardware in a preliminary engine design phase, simple models of component performance in terms of operating conditions are used.

\section{High-pressure Turbine}

Writing mass flow rate equation at station 4 and 4.5 in terms of the flow properties and MFP gives

$$
\dot{m}_{4}=\frac{P_{t 4}}{\sqrt{T_{t 4}}} A_{4} \operatorname{MFP}\left(M_{4}\right)=\dot{m}_{3}\left(1+f_{b}\right)
$$

and

$$
\dot{m}_{4.5}=\frac{P_{t 4.5}}{\sqrt{T_{t 4.5}}} A_{4.5} \operatorname{MFP}\left(M_{4.5}\right)=\dot{m}_{3}\left(1+f_{b}+f_{i t b}\right)
$$

Rearranging Eqs. (3) and (4), and equating $\dot{m}_{3}$ yields

$$
\frac{P_{t 4.4}}{P_{t 4}} \frac{\sqrt{T_{t 4}}}{\sqrt{T_{t 4.5}}} A_{4.5}=A_{4} \frac{\operatorname{MFP}\left(M_{4}\right)}{\operatorname{MFP}\left(M_{4.5}\right)} \frac{\left(1+f_{b}+f_{i t b}\right)}{\left(1+f_{b}\right)} \frac{P_{t 4.4}}{P_{t 4.5}}
$$


The right-hand side of the above equation is considered constant because of the following assumptions: the flow is choked at stations 4 and 4.5 , the flow area at station 4 is constant, variation of fuel-air ratios $(f)$ are ignored compared to unity and the total pressure ratio of ITB is constant. Using referencing, it yields

$$
\frac{P_{t 4.4}}{P_{t 4}} \frac{\sqrt{T_{t 4}}}{\sqrt{T_{t 4.5}}} A_{4.5}=\left(\frac{P_{t 4.4}}{P_{t 4}} \frac{\sqrt{T_{t 4}}}{\sqrt{T_{t 4.5}}} A_{4.5}\right)_{R}
$$

Rearranging and solving for $\pi_{t H}\left(=P_{t 4.4} / P_{t 4}\right)$ yields

$$
\pi_{t H}=\frac{\sqrt{\tau_{t H} \tau_{i t b}}}{\left(\sqrt{\tau_{t H} \tau_{i t b}}\right)_{R}} \frac{A_{4.5 R}}{A_{4.5}} \pi_{t H R}
$$

The equation relating $\pi_{t H}$ and $\tau_{t H}$ comes from $H P T$ efficiency equation:

$$
\tau_{t H}=1-\eta_{t H}\left\{1-\pi_{t H}^{\left(\gamma^{-1}\right) / \gamma_{t}}\right\}
$$

$A_{4.5} / A_{4.5 R}$ is related to the total temperature ratio of the ITB raised to the power of a value $n$ :

$$
A_{4.5} / A_{4.5 R}=\left(\tau_{i t b} / \tau_{i t b R}\right)^{n}
$$

In the case when $n$ equal to $1 / 2$ in Eq. (9), then Eqs. (7) and (8) result in $\pi_{t H}$ and $\tau_{t H}$ being constant at off-design condition. 
Low-pressure Turbine

Writing the mass conservation at stations 4.5 and 8 using $M F P$ and flow properties gives

$$
\pi_{t L}=\pi_{t L R} \sqrt{\frac{\tau_{t L}}{\tau_{t L R}}} \frac{A_{8 R}}{A_{8}} \frac{A_{4.5}}{A_{4.5 R}} \frac{\operatorname{MFP}\left(M_{8 R}\right)}{\operatorname{MFP}\left(M_{8}\right)}
$$

Similarly, $L P T$ efficiency equation gives

$$
\tau_{t L}=1-\eta_{t L}\left\{1-\pi_{t L}^{\left(\gamma_{i t}-1\right) / \gamma_{i t b}}\right\}
$$

One relationship for $A_{8} / A_{8 R}$ is similar to $A_{4.5} / A_{4.5 R}$ except that it is raised to the power of a value $m$

$$
A_{8} / A_{8 R}=\left(\tau_{i t b} / \tau_{i t b R}\right)^{m}
$$

In the case when $m$ equal to $1 / 2$ in Eq. (12) and $M_{8}=M_{8 R}$, then Eqs. (10) and (11) result in $\pi_{L L}$ and $\tau_{t L}$ being constant at off-design condition. With these functional relationships in Eq. (9) and (12), the engine's low pressure turbine performance will vary the same as the turbofan engine without the ITB when the ITB is turned off.

\section{Engine Bypass Ratio}

An expression for the engine bypass ratio is expressed by

$$
\alpha=\frac{\dot{m}_{f}}{\dot{m}_{c}}
$$

In terms of $M F P$ and flow properties, the bypass ratio can be rewritten using referencing as

$$
\alpha=\alpha_{R} \frac{\pi_{c L R} \pi_{c H R} / \pi_{f R}}{\pi_{c L} \pi_{c H} / \pi_{f}} \sqrt{\frac{T_{t 4} / T_{t 4 R}}{\tau_{r} \tau_{f} /\left(\tau_{r R} \tau_{f R}\right)}} \frac{\operatorname{MFP}\left(M_{18}\right)}{\operatorname{MFP}\left(M_{18 R}\right)}
$$

\section{Fan and Low-pressure Compressor}

The equation for the total temperature ratio of the fan, which can be derived directly from the power balance of the low-pressure spool, is written as 


$$
\tau_{f}=1+\left(\tau_{f R}-1\right) \eta_{m L} \frac{\tau_{\lambda-i t b}}{\tau_{r}}\left\{\frac{\left(1-\tau_{t L}\right)\left(1+f_{b}+f_{i t b}\right)}{\tau_{c L R}-1+\alpha\left(\tau_{f R}-1\right)}\right\}
$$

Fan total pressure ratio is given by

$$
\pi_{f}=\left\{1+\eta_{f}\left(\tau_{f}-1\right)\right\}^{\gamma_{c} /\left(\gamma_{c}-1\right)}
$$

Since the $L P C$ and the fan are on the same shaft, it is reasonable to approximate that the total enthalpy rise of $L P C$ is proportional to that of the fan. The use of referencing thus gives

$$
\frac{h_{t 2.5}-h_{t 2}}{h_{t 13}-h_{t 2}}=\frac{\tau_{c L}-1}{\tau_{f}-1}=\left(\frac{\tau_{c L}-1}{\tau_{f}-1}\right)_{R}
$$

Equation above is rewritten to give the $L P C$ total temperature ratio:

$$
\tau_{c L}=1+\left(\tau_{f}-1\right) \frac{\left(\tau_{c L}-1\right)_{R}}{\left(\tau_{f}-1\right)_{R}}
$$

The $L P C$ total pressure ratio is expressed as

$$
\pi_{c L}=\left\{1+\eta_{c L}\left(\tau_{c L}-1\right)\right\}^{\gamma_{c} /\left(\gamma_{c}-1\right)}
$$

High-pressure compressor

From the power balance of the high-pressure spool, solving for the total temperature ratio across $H P C$ gives

$$
\tau_{c H}=1+\eta_{m H}\left(1+f_{b}\right) \frac{\tau_{\lambda-b}\left(1-\tau_{t H}\right)}{\tau_{r} \tau_{c L}}
$$

$H P C$ total pressure ratio is then given by

$$
\pi_{c H}=\left\{1+\eta_{c H}\left(\tau_{c H}-1\right)\right\}^{\gamma_{c} /\left(\gamma_{c}-1\right)}
$$

Exhaust Nozzles

The Mach number at both core (stations 8,9) and fan exhaust nozzles (stations 18, 19) follows directly using 


$$
M_{9}=\sqrt{\frac{2}{\gamma_{i t b}-1}\left\{\left(\frac{P_{t 9}}{P_{9}}\right)^{\frac{\gamma_{i b}-1}{\gamma_{i b}}}-1\right\}}
$$

If $M_{9}>1$, then $M_{8}=1$, else $M_{8}=M_{9}$

$$
M_{19}=\sqrt{\frac{2}{\gamma_{c}-1}\left\{\left(\frac{P_{t 19}}{P_{19}}\right)^{\frac{\gamma_{c}-1}{\gamma_{c}}}-1\right\}}
$$

$$
\text { If } M_{19}>1 \text {, then } M_{18}=1 \text {, else } M_{18}=M_{19}
$$

\section{Engine Mass Flow Rate}

An expression for the overall engine mass flow rate follows by using MFP at station 4, giving

$$
\dot{m}_{0}=\dot{m}_{0 R} \frac{1+\alpha}{1+\alpha_{R}} \frac{P_{0} \pi_{r} \pi_{d} \pi_{c L} \pi_{c H}}{\left(P_{0} \pi_{r} \pi_{d} \pi_{c L} \pi_{c H}\right)_{R}} \sqrt{\frac{T_{t 4 R}}{T_{t 4}}}
$$

\section{Fuel-air Ratios}

Constant Specific Heat model $^{8}$ is used to compute the fuel-air ratios for main burner and ITB.

After the operating conditions for each engine component are determined, it is then possible to calculate the engine performance parameters.

Uninstalled specific thrust can be shown as

$$
\frac{F}{\dot{m}_{0}}=\frac{a_{0}}{g_{c}(1+\alpha)}\left\{\begin{array}{l}
{\left[1+f_{o}(1+\alpha)\right] \frac{V_{9}}{a_{0}}+\alpha \frac{V_{19}}{a_{0}}-(1+\alpha) M_{0}} \\
+\left[1+f_{o}(1+\alpha) \frac{R_{i b}}{R_{c}} \frac{T_{9} / T_{0}}{V_{9} / a_{0}} \frac{\left(1-P_{0} / P_{9}\right)}{\gamma_{c}}\right. \\
+\alpha \frac{T_{19} / T_{0}}{V_{19} / a_{0}} \frac{\left(1-P_{0} / P_{19}\right)}{\gamma_{c}}
\end{array}\right\}
$$

where $f_{o}$ is the total fuel-air ratio per engine inlet airflow, and $a_{0}$ is the sound speed of the incoming air. 
Hence, uninstalled thrust produced by the engine is

$$
F=\dot{m}_{0}\left(\frac{F}{\dot{m}_{0}}\right)
$$

Uninstalled thrust specific fuel consumption (S) is simply obtained by

$$
S=\frac{f_{o}}{F / \dot{m}_{0}}
$$

\section{Engine Controls}

A model for engine control system presented in Mattingly ${ }^{8,9}$ is included into off-design analysis. It is necessary because it avoids compressor stalls or surges and also ensures that maximum limits on internal pressures, and turbine entry temperatures are not exceeded. In addition, $n$ equal to $1 / 2$ and $m$ equal to $1 / 2$ are used for area variations at stations 4.5 and 8 , respectively.

\section{Engine Configurations}

Two sets of reference-point engine data at sea level static $(S L S)$ condition are selected, i.e. case A and B, as provided in Table 2. For each case, engine operating with ITB on is termed as ITB engine. While ITB is turned off, it is considered as a baseline engine. In addition, the component performance parameters, listed in Table 3, are kept the same for both cases.

For full throttle operation, the maximum inlet $H P T$ total temperature ( $T_{t 4}$ or main burner exit total temperature) and the $L P T$ inlet total temperature ( $T_{t 4.5}$ or ITB exit total temperature) are set to the values as listed in Table 2. For partial throttle operation, the minimum thrust is set to 20 percent of the maximum thrust. 
A program was written in combination among Microsoft ${ }^{\circledR}$ Excel spreadsheet neuron cells, VisualBasic, and macro code to provide user-friendly interface so that the compilation and preprocessing are not needed.

\section{Predicted Performance Results}

\section{Full Throttle Performance}

Figures 3a-c present the uninstalled performance of the turbofan engines operating at full throttle settings for case A. These figures show the variations of thrust and thrust specific fuel consumption $(S)$ with flight Mach number $\left(M_{0}\right)$ and altitude, respectively. Two different altitudes are $S L S$ condition and $10 \mathrm{~km}$. The solid lines represent ITB engine performance while the dashed lines represent baseline engine performance. While specific thrust is presented in on-design cycle analysis, thrust is commonly presented in off-design cycle analysis. As shown in Eq. (29), thrust accounts for the variation in both specific thrust and mass flow rate.

In Fig. 3a, ITB engines at two different altitudes exhibit an increase in thrust over the baseline engine as $M_{0}$ increases. Because of more fuel injected into ITB in addition to the main burner, $I T B$ engines do have slightly higher fuel consumption than the baseline engine. Nevertheless, adding ITB is still beneficial because the improvement in thermal efficiency (Fig 3c) reflects that the gain in thrust offsets the slight increase in $S$. In addition, ITB engines perform even better at supersonic flight because there is no increase in $S$ at all as $M_{0}$ is greater than 1.1.

In Figs. $3 \mathrm{a}$ and $3 \mathrm{c}$, both thrust and thermal efficiency curves at $10 \mathrm{~km}$ exhibits a slope change at a $M_{0}$ of 1.2. The engine control system takes place at that operating point in order to limit the main burner exit temperature from exceeding the maximum inlet turbine temperature limit.

Figures 4a-c present the uninstalled performance of the turbofan engines operating at full

throttle settings for case B. It is found that both engines have similar performance trends over the 
flight spectrum as in case A. While gaining higher thrust, ITB engine at $10 \mathrm{~km}$ starts consuming less fuel at $M_{0}$ greater than 0.7.

\section{Partial Throttle Performance}

Figures 5a-b (case A) and 6a-b (case B) show the 'S versus thrust' and 'Thermal efficiency versus thrust' curves at partial throttle settings for three different values of $M_{0}$ at an altitude of 10km. In Figs. 5a and 6a, the curves for ITB engines preserve the classical hook shape that is known as "throttle hook" in the propulsion community. The "neck" of each "hook" is the operating condition where the ITB is being shut off, resulting in a change in slope from a linear curve to a spline. This change is accompanied by an abrupt increase in $S$ and a drop in thrust. As the throttle (i.e. $T_{t 4}$ ) is further reduced, $S$ will decrease slightly and start to increase at lower throttle settings.

According to Figs. 5a and 6a, it is clearly noticed that adding ITB further extends the engine operational range by producing higher thrust at lower $S$ than that of a baseline engine. Further extending to full throttle setting, ITB engines may or may not yield a higher $S$ than that of a baseline engine. For example, the fuel consumption for ITB engines at full load in case B is always lower while it is equal to or higher than that of baseline engine in case A. Therefore, to take full advantage of ITB, i.e., higher thrust at lower $S$, it is good enough to run the ITB engine at partial throttle settings. In addition, it is at partial-throttle setting where the highest thermal efficiency is attained, as shown in Figs. $5 \mathrm{~b}$ and $6 \mathrm{~b}$. This will provide fuel saving to many aircraft engines, which normally run at partial throttle settings during cruise operations at high altitude. However, one drawback is that when ITB is turned off, ITB engine will consume more fuel to produce the same amount of thrust as a baseline engine.

\section{Mission Analysis}


A systematic mission studies of the fuel consumption is performed to reveal the advantage of saving fuel by adding ITB. However, at the preliminary design phase the engine manufacturer's published data is often unavailable; therefore, the off-design engine model like this one can be used to give a preliminary estimate of fuel consumption in each mission phase ${ }^{9}$. A $5 \%$ installation loss is accounted to give the mission analysis fuel consumption.

For the following mission study, only case A is considered. For simplicity, only critical mission phases and segments are selected. Each selected mission leg is judged to be critical because it has a high fuel consumption and is an extreme operating condition ${ }^{9}$. In each mission leg, the ITB engine is operating at partial load to attain the highest thermal efficiency as previously discussed.

Table 4 contains a summary of the mission performance of ITB engine (case A) as compared to baseline engine in term of fuel consumption. Each aircraft has an initial take-off weight of $24,000 \mathrm{lbf}$. It is found that ITB engine uses less fuel in all phases. Particularly, the fuel consumption in the Warm-up (1-2) phase is significantly less. This calculation also shows that $I T B$ engine consumes about 3\% less fuel for all those selected critical mission legs, which assure the fuel efficiency of an ITB engine over the baseline engine. To get an even better fuel consumption, one is free to return to the on-design cycle analysis ${ }^{2}$ and choose other referencepoint engines for further investigation.

\section{Conclusions}

A performance cycle analysis of a separate-flow and two-spool turbofan with ITB has been presented. The mathematical modeling of each engine component (e.g. compressors, burners, turbines and exhaust nozzles), in terms of its operating condition has been systematically described. Results of this study can be summarized as follows: 
1) ITB engine at full throttle setting has enhanced performance over baseline engine.

2) ITB runs very efficiently at partial throttle setting, i.e., higher thrust at lower $S$ than baseline engine. Furthermore, highest thermal efficiency is attained at this point.

3) At ITB-off condition, ITB engine consumes more fuel to produce the same amount of thrust as a baseline engine.

4) Mission study assures the ITB engine's advantage of saving fuel over the baseline engine.

\section{References}

${ }^{1}$ Zucrow, M. J., “Aircraft and Missile Propulsion: Volume II”, John Wiley \& Sons, Inc., 1964

${ }^{2}$ Liew, K. H., Urip, E., Yang, S. L., and Siow, Y. K., A Complete Parametric Cycle Analysis of a Turbofan with Interstage Turbine Burner, AIAA-2003-0685, $41^{\text {st }}$ AIAA Aerospace Sciences Meeting and Exhibit, Reno, NV, January, 2003.

${ }^{3}$ Liu, F. and Sirignano, W.A., "Turbojet and Turbofan Engine Performance Increases Through Turbine Burners," Journal of Propulsion and Power, Vol 17, No. 3, May-June 2001, pp. 695705.

${ }^{4}$ Sirignano, W.A., and Liu, F., "Performance Increases for Gas-Turbine Engines Through Combustion Inside the Turbine," Journal of Propulsion and Power, Vol. 15, No. 1, JanuaryFebruary 1999, pp. 111-118.

${ }^{5}$ Vogeler, K., “The Potential of Sequential Combustion For High Bypass Jet Engines”, ASME 98-GT-311, Proceedings of the 1998 Int'l Gas Turbine \& Aeroengine Congress \& Exhibition, Stockholm, Sweden, 2-5 June 1998. 
${ }^{6}$ Oates, G. C., Aerothermodynamics of Gas Turbine and Rocket Propulsion, $2{ }^{\text {nd }}$ Edition, AIAA Education Series, AIAA, Washington, DC, 1988, pp. 277-296.

${ }^{7}$ "Gas Turbine Engine Performance Station Identification and Nomenclature," Aerospace Recommended Practice (ARP) 755A, SAE, Warrendale, PA, 1974.

${ }^{8}$ Mattingly, J. D., "Elements of Gas Turbine Propulsion”, McGraw Hill, Inc. New York, NY 1996, pp. 18-31, 114-123, 240-246, 256-299, 346-361, 392-405.

${ }^{9}$ Mattingly, J. D., Heiser, W. H., and Pratt, D. T., “Aircraft Engine Design”, $2^{\text {nd }}$ ed., AIAA Education Series, AIAA, 2002, pp. 55-92, 139-162, 577-587. 


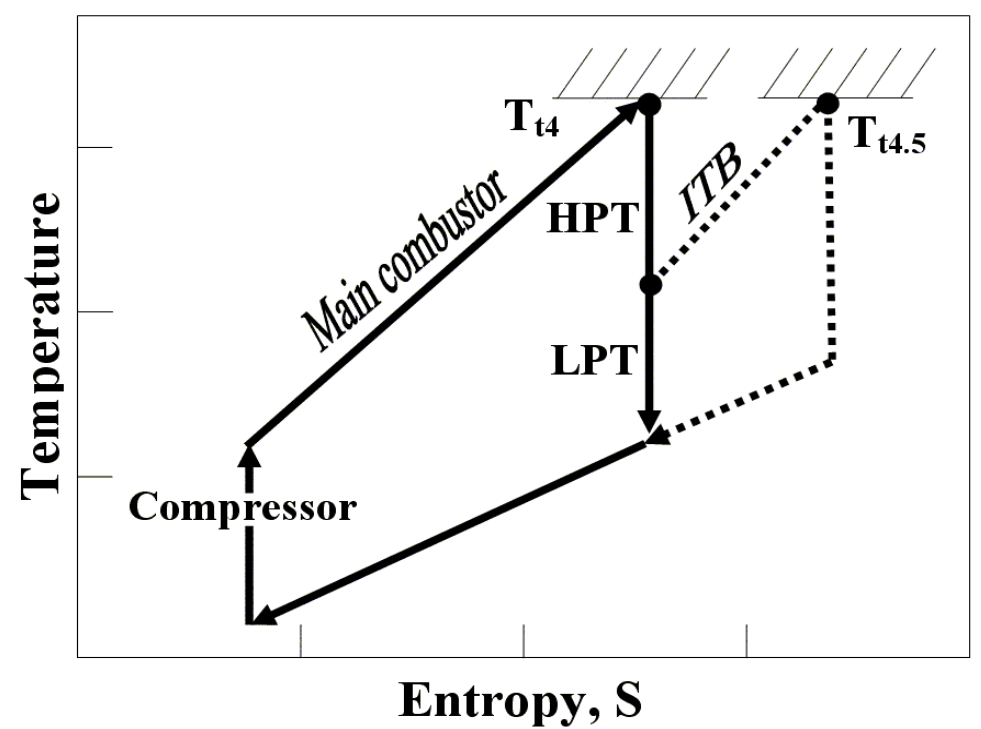

Figure 1. $T$-s diagram of a gas turbine engine with $I T B$

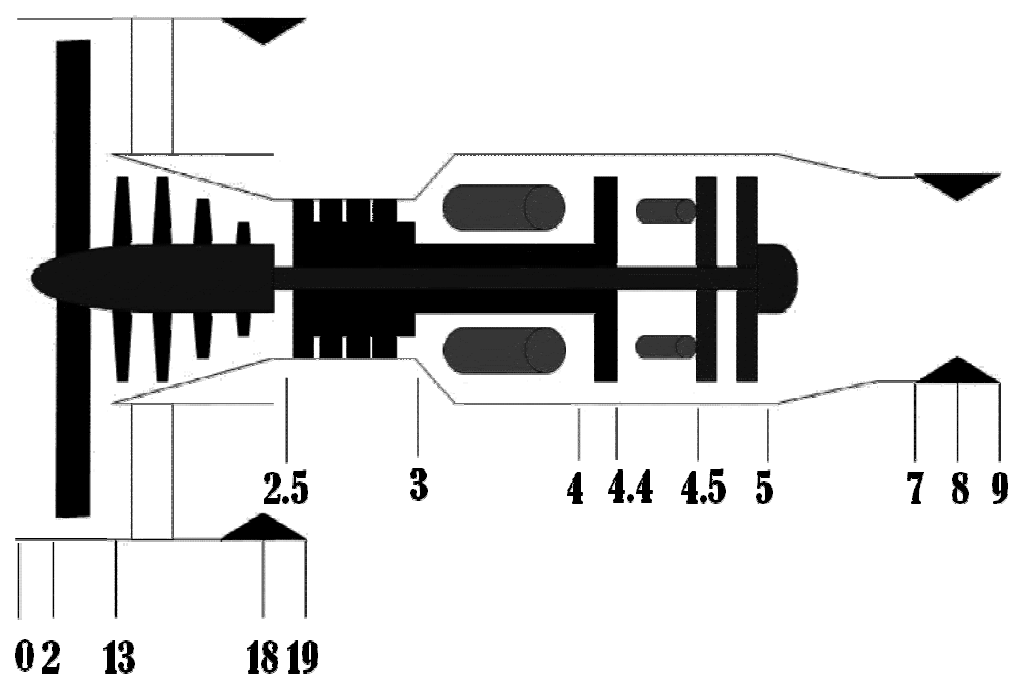

Figure 2. Station numbering of a turbofan engine with ITB 


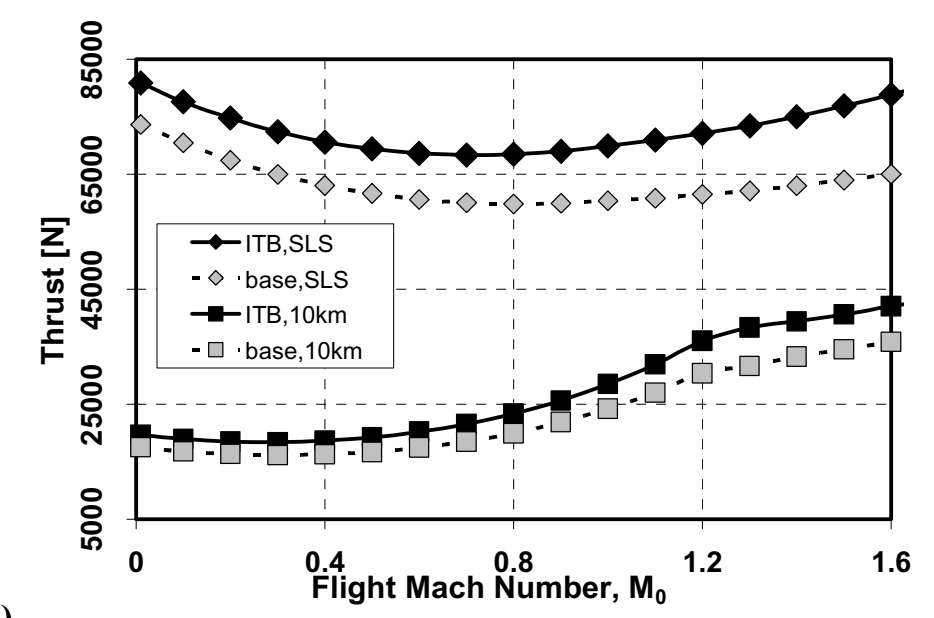

(a)

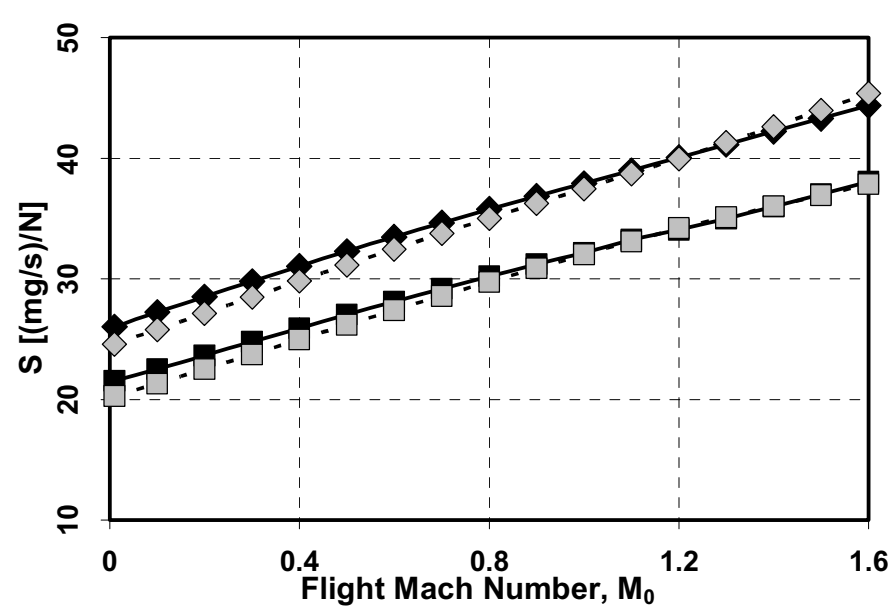

(b)

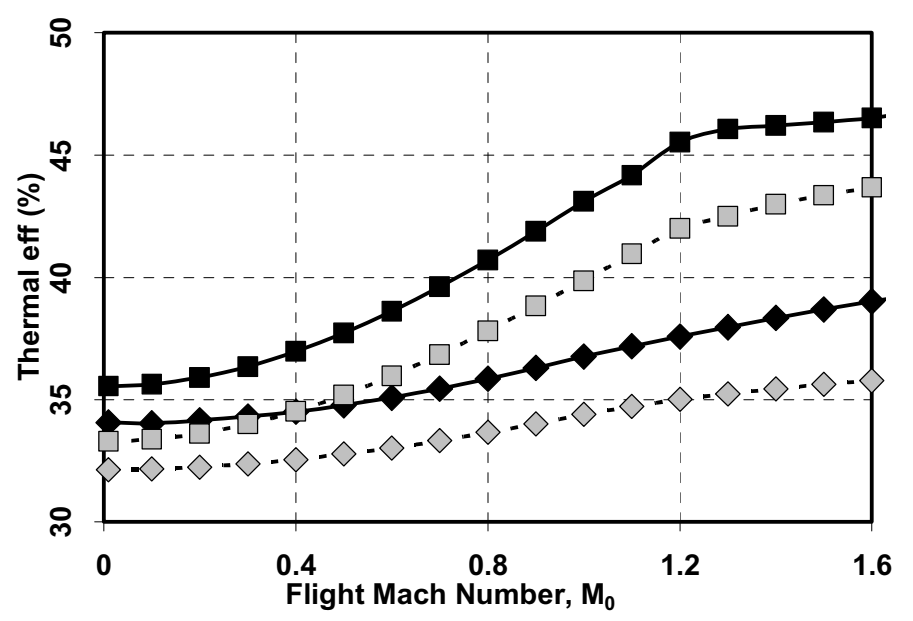

Figure 3. Full-throttle performance comparison of turbofan engines (case A) versus $M_{0}, \pi_{f R}$ $=2.43, \pi_{c R}=20, T_{t 4 R}=1450 \mathrm{~K}, \boldsymbol{T}_{t 4.5 R}=1350 \mathrm{~K}, \dot{m}_{0 R}=118 \mathrm{~kg} / \mathrm{s}$, and $\alpha_{R}=0.73$. 


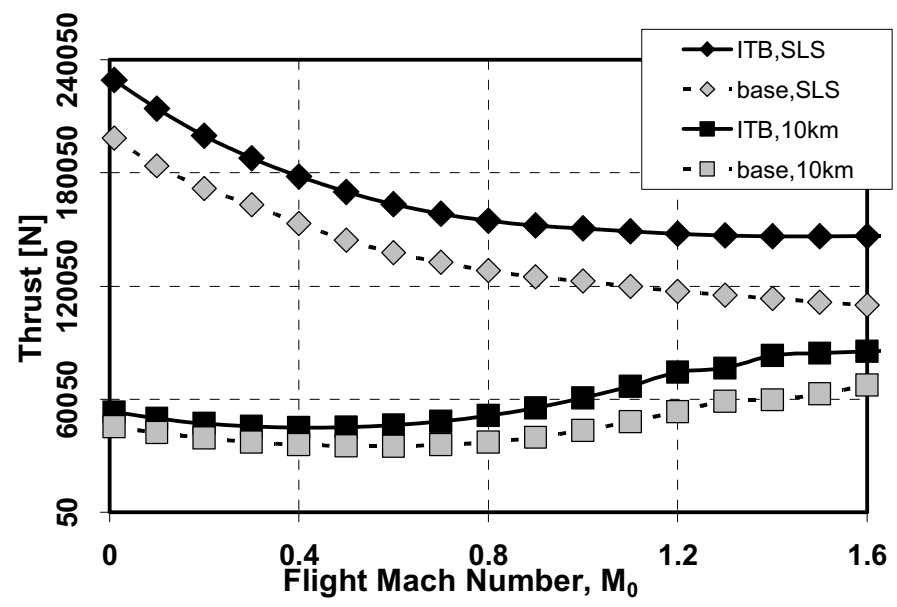

(a)

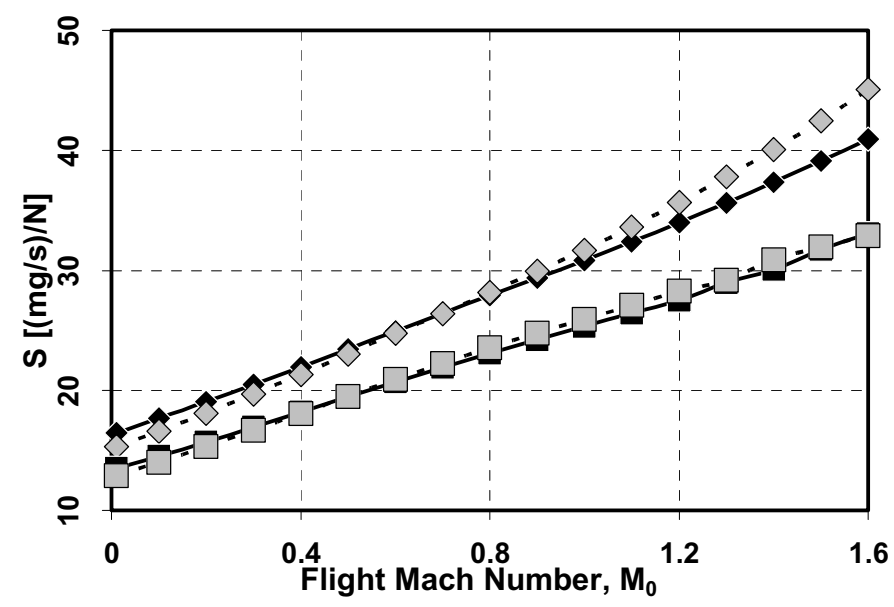

(b)

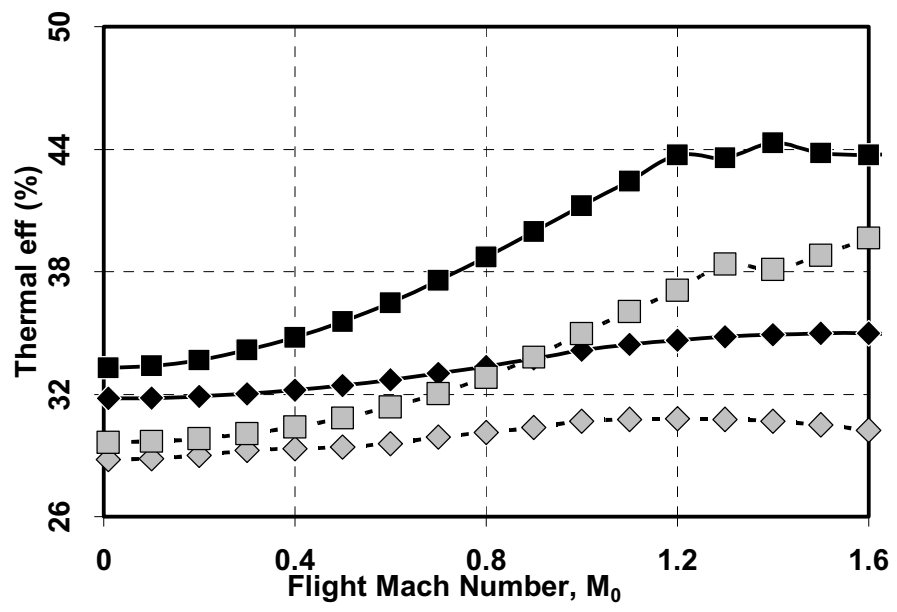

(c)

Figure 4. Full-throttle performance comparison of turbofan engines (case B) versus $M_{0}$, $\pi_{f R}=2.2, \pi_{c R}=25, T_{t 4 R}=1550 \mathrm{~K}, T_{t 4.5 R}=1450 \mathrm{~K}, \dot{m}_{0 R}=540 \mathrm{~kg} / \mathrm{s}$, and $\alpha_{R}=4.0$. 
(a)
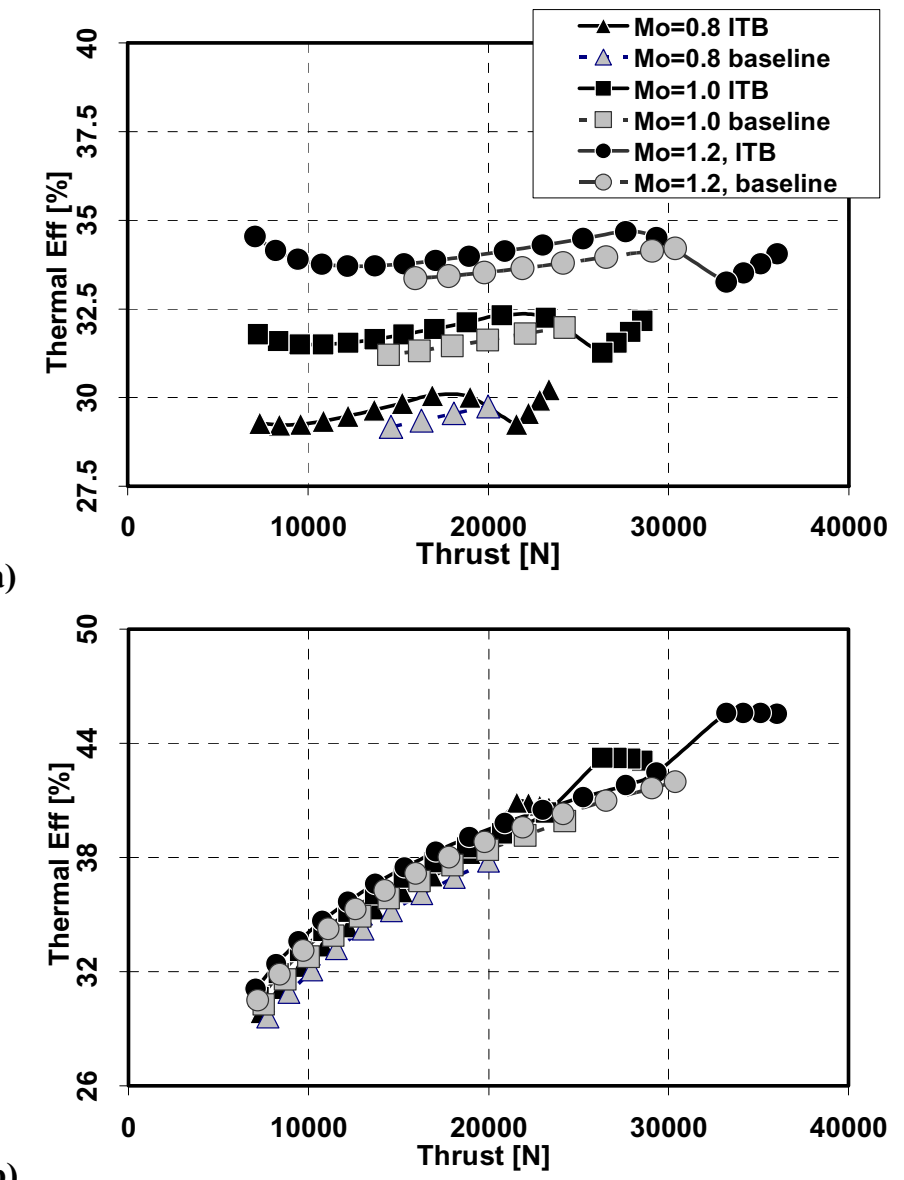

(b)

Figure 5. Partial-throttle performance of turbofan engine (case $A$ ) at altitude of $10 \mathrm{~km}, \pi_{f R}$ $=2.43, \pi_{c R}=20, T_{t 4 R}=1450 \mathrm{~K}, T_{t 4.5 R}=1350 \mathrm{~K}, \dot{m}_{0 R}=118 \mathrm{~kg} / \mathrm{s}$, and $\alpha_{R}=0.73$. 


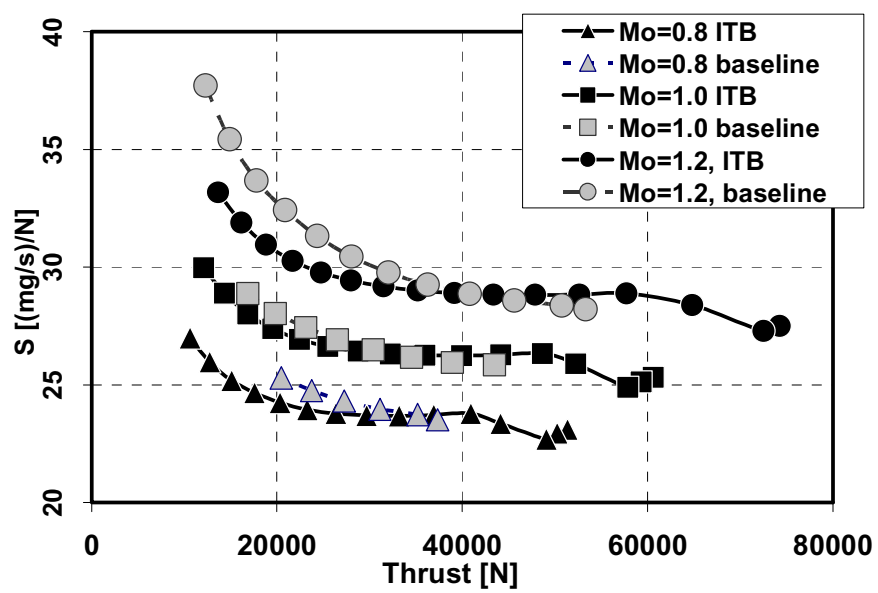

(a)

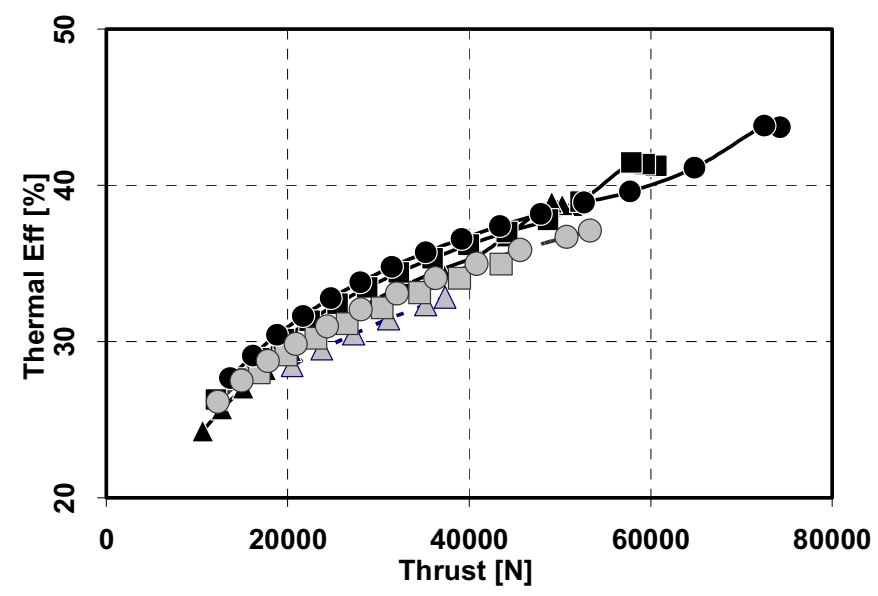

(b)

Figure 6. Partial-throttle performance of turbofan engine (case B) at altitude of $10 \mathrm{~km}, \pi_{f R}$ $=2.2, \pi_{c R}=25, T_{t 4 R}=1550 \mathrm{~K}, T_{t 4.5 R}=1450 \mathrm{~K}, \dot{m}_{0 R}=540 \mathrm{~kg} / \mathrm{s}$, and $\alpha_{R}=4.0$. 
Table 1. Engine Performance Variables

\begin{tabular}{lccc}
\hline Component & $\begin{array}{c}\text { Independent } \\
\text { Variable } \\
M_{0}, T_{0}, P_{0}\end{array}$ & $\begin{array}{c}\text { Constant } \\
\text { or Known }\end{array}$ & $\begin{array}{c}\text { Dependent } \\
\text { Variable } \\
\dot{m}_{0}, \alpha\end{array}$ \\
engine & & $\pi_{d}=f\left(M_{0}\right)$ & \\
diffuser & & $\eta_{f}$ & $\pi_{f}, \tau_{f}$ \\
fan & & $\eta_{c L}$ & $\pi_{c L}, \tau_{c L}$ \\
low-pressure compressor & $T_{t 4}$ & $\eta_{b H}$ & $\pi_{c H}, \tau_{c H}$ \\
high-pressure compressor & & $\eta_{t H}, M_{4}$ & $\pi_{t H}, \tau_{t H}$ \\
burner & $T_{t 4.5}$ & $\pi_{i t b}$ & $f_{i t b}$ \\
high-pressure turbine & $n$ & $\eta_{t L}, M_{4.5}$, & $\pi_{t L}, \tau_{t L}$ \\
inter-stage burner & & $A_{4.5}=f\left(\tau_{i t b}, n\right)$ & $M_{18}, M_{19}$ \\
low-pressure turbine & & $\pi_{f n}$ & $M_{8}, M_{9}$ \\
fan exhaust nozzle & $m$ & $\pi_{n}$, & 18 \\
core exhaust nozzle & & $A_{8}=f\left(\tau_{i t b}, m\right)$ & \\
& 7 & &
\end{tabular}

Table 2. Design-point engine reference data

\begin{tabular}{|lcc|}
\hline Reference Conditions & Case A & Case B \\
\hline Mach number $\left(M_{0 R}\right)$ & 0 & 0 \\
Altitude $\left(h_{R}\right)$ & $S L S$ & $S L S$ \\
Main burner exit total temperature $\left(T_{t 4 R}, \mathrm{~K}\right)$ & 1450 & 1550 \\
$I T B$ exit temperature $\left(T_{t 4.5 R}, \mathrm{~K}\right)$ & 1350 & 1450 \\
Compressor pressure ratio $\left(\pi_{c R}\right)$ & 20 & 25 \\
Fan pressure ratio $\left(\pi_{f R}\right)$ & 2.43 & 2.2 \\
Fan bypass ratio $\left(\alpha_{R}\right)$ & 0.73 & 4.0 \\
Mass flow rate $\left(\dot{m}_{0 R}, \mathrm{~kg} / \mathrm{s}\right)$ & 118 & 540 \\
\hline
\end{tabular}


Table 3. Engine component parameters

\begin{tabular}{|cc|}
\hline Component Parameters & Input value \\
\hline Total pressure ratios & \\
Inlet $\left(\pi_{d, m a x}\right)$ & 0.99 \\
Main burner $\left(\pi_{b}\right)$ & 0.95 \\
$I T B\left(\pi_{I T B}\right)$ & 0.95 \\
Nozzle $\left(\pi_{n}\right)$ & 0.99 \\
Fan nozzle $\left(\pi_{f n}\right)$ & 0.98 \\
Efficiencies & \\
Main burner $\left(\eta_{b}\right)$ & 0.99 \\
$I T B\left(\eta_{i t b}\right)$ & 0.99 \\
$H P$ spool $\left(\eta_{m-H P}\right)$ & 0.92 \\
$L P$ spool $\left(\eta_{m-L P}\right)$ & 0.93 \\
Polytropic Efficiencies & \\
Fan $\left(e_{f}\right)$ & 0.93 \\
$L P$ Compressor $\left(e_{c L}\right)$ & 0.8738 \\
$H P$ Compressor $\left(e_{c H}\right)$ & 0.9085 \\
$H P$ Turbine $\left(e_{t H}\right)$ & 0.8999 \\
$L P$ Turbine $\left(e_{t L}\right)$ & 0.9204 \\
Fuel low heating value $\left(h_{P R}\right)$ & $43,124 \mathrm{~kJ} / \mathrm{kg}$ \\
\hline
\end{tabular}

Table 4. Summary of results for mission analysis (24,000 lbf of take-off weight)

\begin{tabular}{|c|c|c|c|c|c|c|}
\hline \multirow[b]{2}{*}{ Mission phases and segments } & \multirow[b]{2}{*}{$\mathbf{M}_{0}$} & \multirow[b]{2}{*}{ Alt (kft) } & \multirow{2}{*}{$\begin{array}{c}\text { Baseline } \\
\begin{array}{c}\text { Fuel used } \\
\text { (lbf) }\end{array}\end{array}$} & \multirow{2}{*}{$\begin{array}{c}\text { ITB } \\
\begin{array}{c}\text { Fuel used } \\
\text { (Ibf) }\end{array}\end{array}$} & \multirow[b]{2}{*}{$\begin{array}{c}\text { Fuel saved, } \\
\text { (lbf) }\end{array}$} & \multirow[b]{2}{*}{$\begin{array}{c}\text { Fuel } \\
\text { saved (\%) }\end{array}$} \\
\hline & & & & & & \\
\hline \begin{tabular}{l|l|}
$1-2$ & A - Warm up
\end{tabular} & 0.0 & 2 & 414 & 343 & 71 & 17.2 \\
\hline 2-3 E - Climb/acceleration & 0.875 & 23 & 483 & 474 & 9 & 1.9 \\
\hline 3-4|Subsonic cruise climb & 0.9 & 42 & 509 & 500 & 9 & 1.7 \\
\hline 5-6 $\mid$ Combat air patrol & 0.697 & 30 & 714 & 701 & 13 & 1.9 \\
\hline 6-7 |F - Acceleration & 1.09 & 30 & 247 & 244 & 3 & 1.3 \\
\hline 6-7 G - Supersonic penetration & 1.5 & 30 & 1774 & 1713 & 61 & 3.4 \\
\hline $7-8 \mid \mathrm{I}-1.6 \mathrm{M} / 5 \mathrm{~g}$ turn & 1.6 & 30 & 414 & 401 & 14 & 3.3 \\
\hline 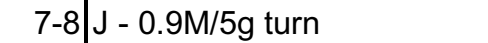 & 0.9 & 30 & 297 & 291 & 5 & 1.8 \\
\hline 7-8 K - Acceleration & 1.2 & 30 & 228 & 225 & 3 & 1.2 \\
\hline 8-9 Escape dash & 1.5 & 30 & 518 & 503 & 16 & 3.1 \\
\hline 10-11 Subsonic cruise climb & 0.9 & 48 & 462 & 457 & 5 & 1.0 \\
\hline 12-13|Loiter & 0.378 & 10 & 631 & 624 & 7 & 1.1 \\
\hline & & Total & 6691 & 6475 & 216 & 3.2 \\
\hline
\end{tabular}




\section{List of Figures}

Figure 1. T-s diagram of a gas turbine engine with ITB

Figure 2. Station numbering of a turbofan engine with ITB

Figure 3. Full-throttle performance comparison of turbofan engines (case A) versus $M_{0}, \pi_{f R}=\mathbf{2 . 4 3}, \pi_{c R}=\mathbf{2 0}$, $T_{t 4 R}=1450 \mathrm{~K}, T_{t 4.5 R}=1350 \mathrm{~K}, \dot{m}_{0 R}=118 \mathrm{~kg} / \mathrm{s}$, and $\alpha_{R}=0.73$.

Figure 4. Full-throttle performance comparison of turbofan engines (case B) versus $M_{0}, \pi_{f R}=\mathbf{2 . 2}, \pi_{c R}=\mathbf{2 5}$, $T_{t 4 R}=1550 \mathrm{~K}, T_{t 4.5 R}=1450 \mathrm{~K}, \dot{m}_{0 R}=540 \mathrm{~kg} / \mathrm{s}$, and $\alpha_{R}=4.0$.

Figure 5. Partial-throttle performance of turbofan engine (case A) at altitude of $10 \mathrm{~km}, \pi_{f R}=\mathbf{2 . 4 3}, \pi_{c R}=\mathbf{2 0}$, $T_{t 4 R}=1450 \mathrm{~K}, T_{t 4.5 R}=1350 \mathrm{~K}, \dot{m}_{0 R}=118 \mathrm{~kg} / \mathrm{s}$, and $\alpha_{R}=0.73$.

Figure 6. Partial-throttle performance of turbofan engine (case B) at altitude of $10 \mathrm{~km}, \pi_{f R}=2.2, \pi_{c R}=25, T_{t 4 R}$ $=1550 \mathrm{~K}, T_{t 4.5 R}=1450 \mathrm{~K}, \dot{m}_{0 R}=540 \mathrm{~kg} / \mathrm{s}$, and $\alpha_{R}=4.0$.

\section{List of Tables}

Table 1. Engine Performance Variables

Table 2. Design-point engine reference data

Table 3. Engine component parameters

Table 4. Summary of results for mission analysis $(24,000 \mathrm{lbf}$ of take-off weight) 


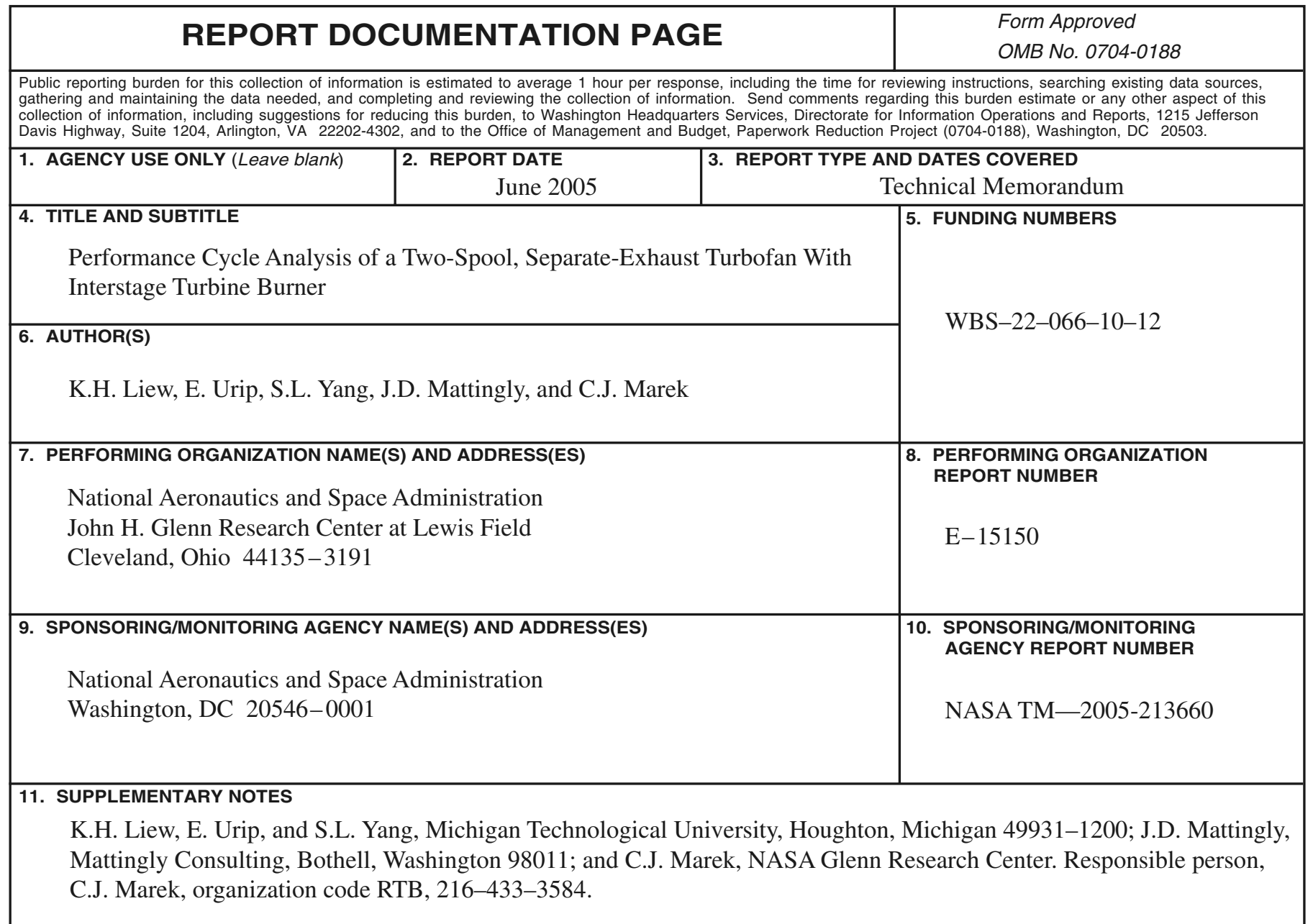

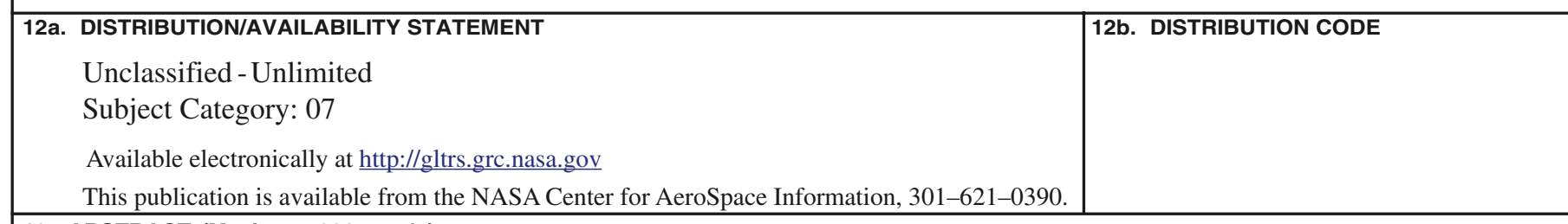

13. ABSTRACT (Maximum 200 words)

This paper presents the performance cycle analysis of a dual-spool, separate-exhaust turbofan engine, with an Interstage Turbine Burner serving as a secondary combustor. The ITB, which is located at the transition duct between the high- and the low-pressure turbines, is a relatively new concept for increasing specific thrust and lowering pollutant emissions in modern jet engine propulsion. A detailed performance analysis of this engine has been conducted for steady-state engine performance prediction. A code is written and is capable of predicting engine performances (i.e., thrust and thrust specific fuel consumption) at varying flight conditions and throttle settings. Two design-point engines were studied to reveal trends in performance at both full and partial throttle operations. A mission analysis is also presented to assure the advantage of saving fuel by adding ITB.

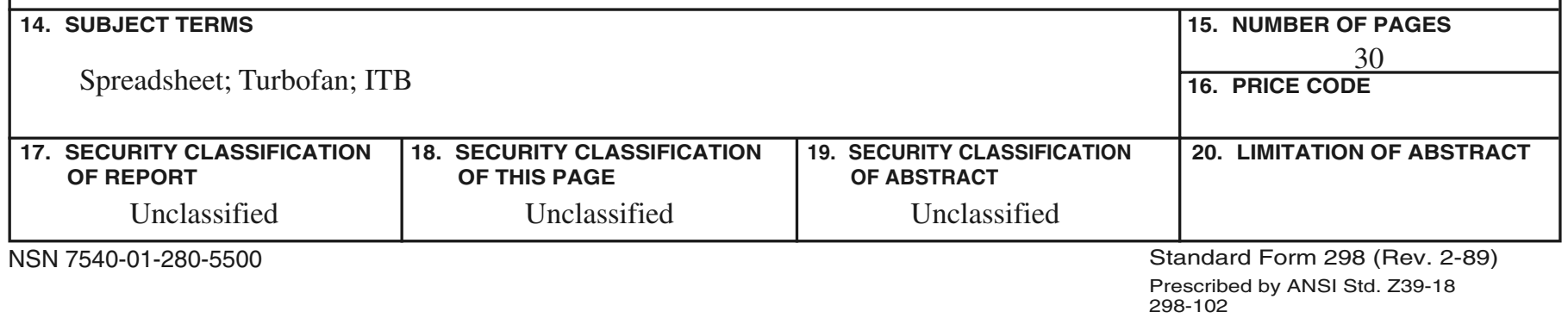



